\title{
Article \\ Comparison of the Amplitude of Accommodation Measured Using a New-Generation Closed-Field Autorefractor with Conventional Subjective Methods
}

\author{
Piotr Kanclerz ${ }^{1, *(D)}$, Karolina Pluta ${ }^{1,2}$, Hamed Momeni-Moghaddam ${ }^{3}$ and Ramin Khoramnia 4 (D) \\ 1 Department of Ophthalmology, Hygeia Clinic, 80-286 Gdansk, Poland; karolinawieslawapluta@gmail.com \\ 2 Medical University of Gdansk, 80-210 Gdansk, Poland \\ 3 Health Promotion Research Center, Zahedan University of Medical Sciences, Zahedan 9816743463, Iran; \\ hmomeni_opt@yahoo.com \\ 4 The David J. Apple International Laboratory for Ocular Pathology, Department of Ophthalmology, \\ University of Heidelberg, 69120 Heidelberg, Germany; ramin.khoramnia@med.uni-heidelberg.de \\ * Correspondence: p.kanclerz@gumed.edu.pl; Tel./Fax: +48-58-776-40-46
}

Citation: Kanclerz, P.; Pluta, K.; Momeni-Moghaddam, H.;

Khoramnia, R. Comparison of the Amplitude of Accommodation Measured Using a New-Generation Closed-Field Autorefractor with Conventional Subjective Methods. Diagnostics 2022, 12, 568. https:// doi.org/10.3390/diagnostics 12030568

Academic Editors: Elina A. Genina and Vassilios P. Kozobolis

Received: 15 December 2021 Accepted: 21 February 2022 Published: 23 February 2022

Publisher's Note: MDPI stays neutral with regard to jurisdictional claims in published maps and institutional affiliations.

Copyright: (c) 2022 by the authors Licensee MDPI, Basel, Switzerland. This article is an open access article distributed under the terms and conditions of the Creative Commons Attribution (CC BY) license (https:// creativecommons.org/licenses/by/ $4.0 /)$.

\begin{abstract}
Purpose: This study aims to compare and assess the agreement of the objective amplitude of accommodation (AA) measured using a new-generation closed-field autorefractor with conventional subjective methods. Methods: In total, 84 healthy individuals with an age range of 19 to 50 years participated in this cross-sectional study. AA was measured objectively with a Nidek autorefractor (AR-1a; Nidek Co., Ltd., Tokyo, Japan) and subjectively using push-up (PU) and minus-lens (ML) methods in a random order. Comparison between different methods was performed using repeatedmeasures analysis of variance and the Bonferroni test for pairwise comparisons. In addition to the Pearson correlation, the Bland and Altman method and the intraclass correlation coefficient were used to determine the agreement between the three techniques. Only the right-eye results were used for analysis. Results: AA measured using the Nidek autorefractor ( $3.43 \pm 1.94 \mathrm{D})$ was significantly lower than that measured with PU $(7.67 \pm 2.38 \mathrm{D} ; p<0.001)$ and ML $(7.60 \pm 2.81 \mathrm{D} ; p<0.001)$ methods. The difference between the subjective methods was not significant statistically $(p=1.0)$. The correlation for Nidek measurements and PU and ML methods was moderate $(r=0.5502$ and $r=0.6832$, respectively), while it was strong when comparing subjective methods $(r=0.7821)$. The limits of agreement for Nidek vs. PU, Nidek vs. ML, and PU vs. ML methods were -8.28 to $-0.23 \mathrm{D},-8.19$ to $-0.15 \mathrm{D}$, and -3.38 to $3.51 \mathrm{D}$, respectively. Conclusions: There was a moderate agreement between AA obtained with subjective methods and objective Nidek measurements. The objective AA measurements obtained with a new Nidek autorefractor were significantly lower than subjective measurements.
\end{abstract}

Keywords: amplitude of accommodation; minus-lens method; push-up method; open-field autorefractometry

\section{Introduction}

The accommodative capacity of the eye decreases with age, and this decline becomes clinically relevant from the age of 40 years, resulting in presbyopia [1]. In younger patients, accommodative insufficiency (AI) is a cause of visual fatigue and ocular asthenopia [2], with the prevalence of AI ranging between $1.9 \%$ and $14.7 \%$ in schoolchildren and young adults [3]. Previous studies have shown that the agreement between subjective methods for measuring the amplitude of accommodation (AA) can show significant variability $[4,5]$. Thus, objective measurements in which the oculomotor response to an accommodative stimulus is assessed might provide additional value.

Open-field autorefractors, such as Shin-Nippon SRW-5000 (Rexxam Co., Ltd., Osaka, Japan) or Grand-Seiko WR-5100K (Grand Seiko Co., Ltd., Hiroshima, Japan) models, allow measurements to be obtained while presenting accommodative targets [6]. Viewing 
through an open view is deliberated as a more natural situation that permits a "natural world" environment [7]. Open-field autorefractors have been shown to provide objective AA measurements in several clinical studies [7-11]. Due to their construction, open-field devices allow proximal or lens stimulation to induce an oculomotor response. However, they are mainly used in clinical investigations anddo not have a large market share. In contrast, closed-field autorefractors are typically found in clinical practice, are less expensive, and use internal fixation targets [12]. Although autorefractors have been used for measuring refraction since the 1990s, evaluation of AA in commonly used devices is not available [13]. Nidek Co., Ltd. (Tokyo, Japan) has introduced objective AA assessment into a new series of closed-field autorefractors. This study aims to compare AA measurements obtained using a new-generation autorefractor with conventional subjective methods.

\section{Materials and Methods}

This cross-sectional study enrolled volunteers with healthy eyes at Hygeia Clinic, Gdansk, Poland, in October 2020. The study adhered to the tenets of the Declaration of Helsinki for the use of human participants in biomedical research and was approved by the local ethics committee (KB-21/20). All participants signed informed consent forms after receiving an explanation of the study's objectives.

Before enrollment, the clinical history was collected and both eyes received a complete ophthalmic examination, including assessment of objective refraction refined by the subjective method with the corrected ametropia most plus (CAMP) lens and by accommodative balancing [14]. The inclusion criteria were an age range of 18 to 50 years; best-corrected visual acuity of at least $0.0 \log$ MAR or better in each eye at $4 \mathrm{~m}$ and $40 \mathrm{~cm}$; and no abnormalities of binocular vision at a distance or near, as assessed with a cover test. Subjects with eye diseases, including strabismus, cataract, macular disorders, or inflammation, as well as having undergone intraocular surgery or trauma were excluded. In addition, individuals with a history of systemic diseases, such as diabetes mellitus, anemia, or neurological disorders, and with a history of using ocular and systemic drugs were excluded from this study. The subjective refraction was assessed and subjects were classified as having myopia if the spherical equivalent (SE) was equal to or less than $-0.50 \mathrm{D}$; hyperopia was defined as an SE greater than +1.00 D; and emmetropia, defined as an SE between $+1.00 \mathrm{D}$ and $-0.25 \mathrm{D}[15]$

\subsection{AA Assessment}

Measurements were performed by one of the three experienced examiners (K.P., J.S., and P.K.). For each participant, one examiner assessed AA monocularly in both eyes using three methods in random order; all examinations were performed between 3:00 p.m. and 8:00 p.m. All measurements were performed only once for each method and in the same environment luminance.

Automatic AA measurements are implemented in the new series of Nidek infrared autorefractors (ARK-1a, ARK-1s, AR-1a, AR-1s, AR-F, ARK-F, and Tonoref III; Figure 1). During the AA assessment, participants were seated at the instrument (Nidek AR-1a), with their head stabilized in the instrument chin rest and forehead strap. During the measurement, following routine autorefractometry, the participants were requested to focus on a specific fixation target (a picture of a balloon floating over a road). The device uses a Badal optical system, in which a lens moves internally to alter the accommodative stimulus. The measurement was completed after a maximum of $30 \mathrm{~s}$, and the device reduced the measurement time in cases of slow or poor accommodative response. Repeatability and reproducibility of this particular type of Nidek autorefractors in AA measurement [16], as well as the association between the pupil size and AA [17], have already been evaluated; thus, these aspects were not assessed. 
a

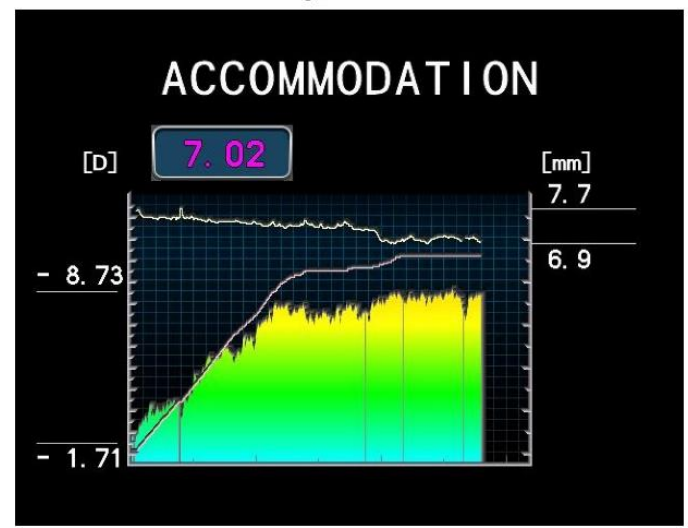

b

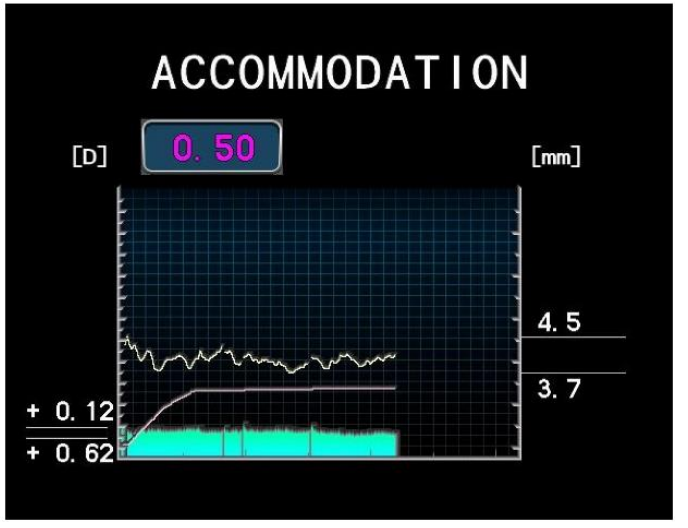

Figure 1. Amplitude of accommodation (AA) and pupil size assessed during the AA measurement in a 25-year-old female (a) and a 53-year-old female (b). The horizontal axis shows the examination time (up to $30 \mathrm{~s}$ ). The colored bars represent the real-time refraction, and the lower continuous line represents the internal target position. On the left vertical axis, the minimal and maximal AA values are presented, while the AA magnitude is presented in the box above the chart. The right vertical axis indicates the minimal and maximal pupillary diameter (continuous pupil size assessment is shown as the upper line). All images were obtained with TONOREF IIIL and reproduced with permission from [17].

Subjective measurements were performed using push-up (PU) and minus-lens (ML) methods. The Royal Air Force (RAF) near-point rule with the reduced Snellen chart was used for the subjective methods. All examinations were performed monocularly under similar testing conditions, with the participants wearing a trial frame with the CAMP lens in front of their eyes. In the PU method, the target was placed $40 \mathrm{~cm}$ from the participants. The target was gradually moved closer to the participants at a speed of around $1 \mathrm{~cm} / \mathrm{s}$ until they reported blur at the 20/30 line; the endpoint was the first sustained blur [18,19]. The distance of the near point of accommodation was read from the scale on the rule to the lens plane in centimeters, converted to diopters, and recorded as AA.

In the ML method, an RAF rule target was placed $33 \mathrm{~cm}$ from the participant. With the CAMP lenses in the trial frame, minus lenses were gradually added in $0.50 \mathrm{D}$ steps in front of one eye, while the other eye was occluded. Participants were asked to try to maintain target clarity until the letters became slightly blurred and could not be cleared. Participants were allowed up to 5-10 s for each lens presentation to clear the target. The participants were also offered to take some rest between measurements. AA was determined by the sum of the absolute power of the last lens before reporting slight sustained blur and the dioptric values of the target distance $(3 \mathrm{D})$.

\subsection{Statistical Analysis}

Statistical analysis was performed using MedCalc v. 14 (MedCalc Software bv, Ostend, Belgium) and IBM SPSS Statistics v. 28 (IBM Corporation, Armonk, NY, USA). The normality of data was assessed using the Kolmogorov-Smirnov test, which showed a normal distribution. The results are presented as the mean \pm standard deviation (SD). Due to the high correlation in AA measured between the two eyes, only the results for the right eye were analyzed. The dependence between age, examiner, and the results of Nidek, PU, and ML AA was checked using the test of between-subject effects. Comparison between the methods was conducted using repeated-measures analysis of variance (ANOVA) with the Bonferroni post hoc test for multiple comparisons and Pearson correlation coefficients. The Bland and Altman method (plotting the differences between the measurements on the vertical axis against their mean on the horizontal axis) was used to assess the absolute agreement between different techniques [20]. Correlation coefficient values between 0 and 0.3 were considered weak positive; between 0.3 and 0.7 , moderate positive; and between 0.7 and 1.0, 
strong positive linear relationships [21]. In addition, the 95\% limits of agreements (LoA; the mean $\pm 1.96 \mathrm{SD}$ of the differences between the two measurement techniques) were calculated. A $p$ value of less than 0.05 was considered significant statistically.

The PS program (version 3.1.6) was used for power and sample size calculations [22]. A sample size of 54 eyes per group was estimated to detect a difference in an AA of $0.5 \mathrm{D}$, based on a standard deviation of the difference between AA methods of 1.0 D, and a power of $95 \%$ at a significance level of $5 \%$.

\section{Results}

Of the 84 subjects who participated in this study, $51(60.7 \%)$ were female. The mean age was $28.6 \pm 7.7$ years, with a range of 19 to 50 years; the age distribution is presented in Figure 2. The mean spherical equivalent refraction was $-0.93 \pm 1.73 \mathrm{D}$ (range -7.25 to $2.88 \mathrm{D}$ ), while the mean refractive cylinder was $-0.62 \pm 0.54 \mathrm{D}$ (range -3.25 to $0 \mathrm{D}$ ). Thirty-eight eyes were myopic $(45.2 \%)$, while six eyes $(7.1 \%)$ were hyperopic; the remaining patients were classified as emmetropes.

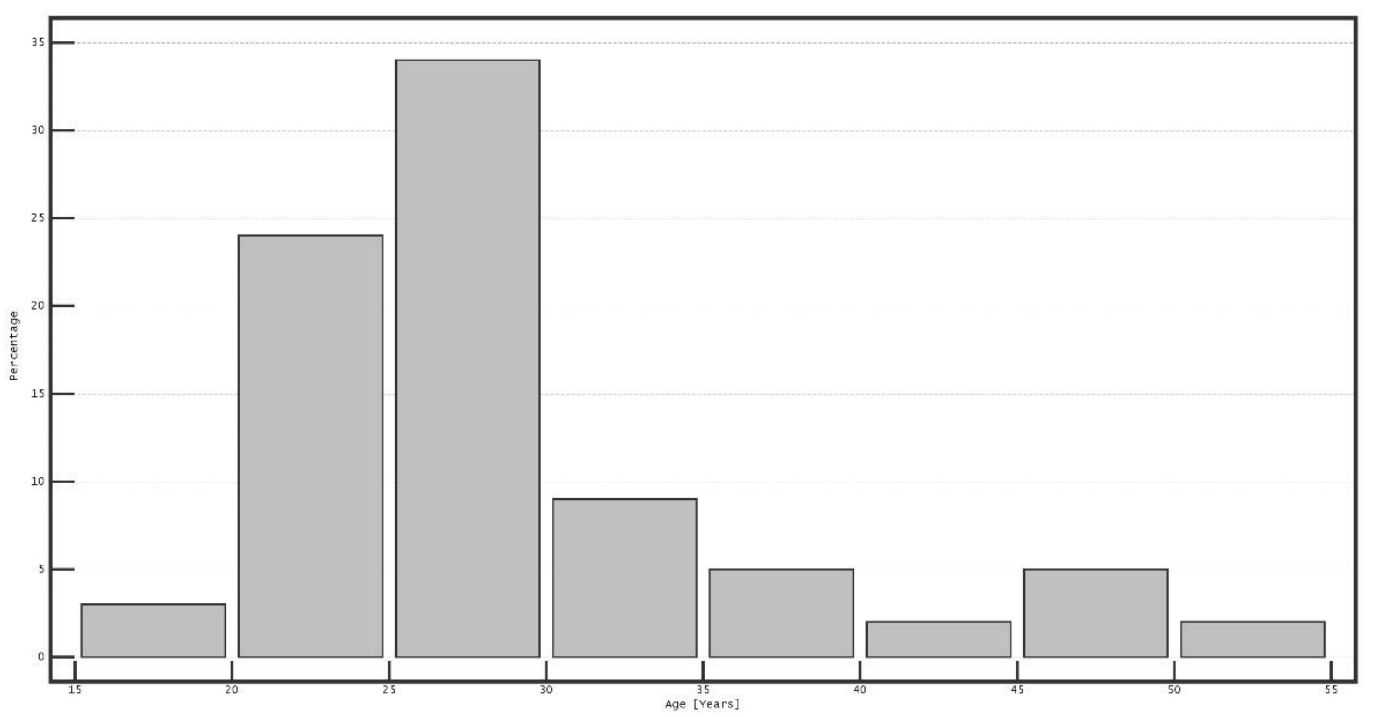

Figure 2. Age distribution of the participants.

The mean \pm SD of AA measured using the Nidek autorefractor and the PU and ML techniques was $3.43 \pm 1.94 \mathrm{D}$ (95\% CI: 3.01 to 3.86), $7.67 \pm 2.38 \mathrm{D}$ (95\% CI: 7.14 to 8.19), and $7.60 \pm 2.81 \mathrm{D}(95 \% \mathrm{CI}: 6.98$ to 8.21$)$, respectively. There was a statistically significant difference between the different techniques using repeated-measures analysis of variance $(p<0.001)$. AA measured with the Nidek autorefractor and the PU and ML methods was dependent on age ( $p<0.001, p<0.001$, and $p<0.001$, respectively) but was independent of the examiner performing the evaluation $(p=0.434, p=0.166$, and $p=0.868$, respectively). The pairwise comparisons showed that AA obtained with the Nidek autorefractor was significantly lower than that obtained by the PU $(p<0.01)$ and ML $(p<0.01)$ methods, while the difference between PU and ML methods was not statistically significant $(p=0.72)$.

The mean difference, the limit of agreement, and the correlation between the three techniques are presented in Table 1. The correlation was strong between PU and ML $(r=0.7821, p<0.001)$ methods and moderate when comparing Nidek measurements with PU and ML $(r=0.5502, p<0.001$, and $r=0.6832, p<0.001$, respectively $)$ methods. The $95 \%$ LoA between the methods was over 8.0 D when comparing the Nidek measurements and subjective methods, which are presented on the Bland-Altman plots in Figures 3 and 4. The 95\% LoA was slightly lower, approximately 7.0 D, between PU and ML methods (Figure 5). 
Table 1. Mean differences, $95 \%$ limits of agreement (LoA), correlation coefficient $(r)$, and pairwise comparison between various methods for assessing the amplitude of accommodation (AA); ( $n=84$ eyes).

\begin{tabular}{ccccc}
\hline Pairwise Comparison & $\begin{array}{c}\text { Mean Difference } \pm \text { SD } \\
\text { (95\% CI) [D] }\end{array}$ & 95\% LoA [D] & $\begin{array}{c}r \\
(p \text { Value })\end{array}$ & $p$ Value \\
\hline \multirow{2}{*}{ Nidek-PU } & $\begin{array}{c}-4.23 \pm 2.04 \\
(-4.79 \text { to }-3.68)\end{array}$ & -8.28 to -0.23 & $\begin{array}{c}0.5502 \\
(<0.001)\end{array}$ & $<0.001$ \\
\hline \multirow{2}{*}{ Nidek-ML } & $\begin{array}{c}-4.16 \pm 2.03 \\
(-4.71 \text { to }-3.61)\end{array}$ & -8.19 to -0.15 & $\begin{array}{c}0.6832 \\
(<0.001)\end{array}$ & $<0.001$ \\
\hline PU-ML & $\begin{array}{c}0.07 \pm 1.75 \\
(-0.40 \text { to } 0.55)\end{array}$ & -3.38 to 3.51 & $\begin{array}{c}0.7821 \\
(<0.001)\end{array}$ & \multirow{2}{*}{1.0} \\
\hline
\end{tabular}

CI: confidence interval; ML: minus lens; PU: push-up; SD: standard deviation.

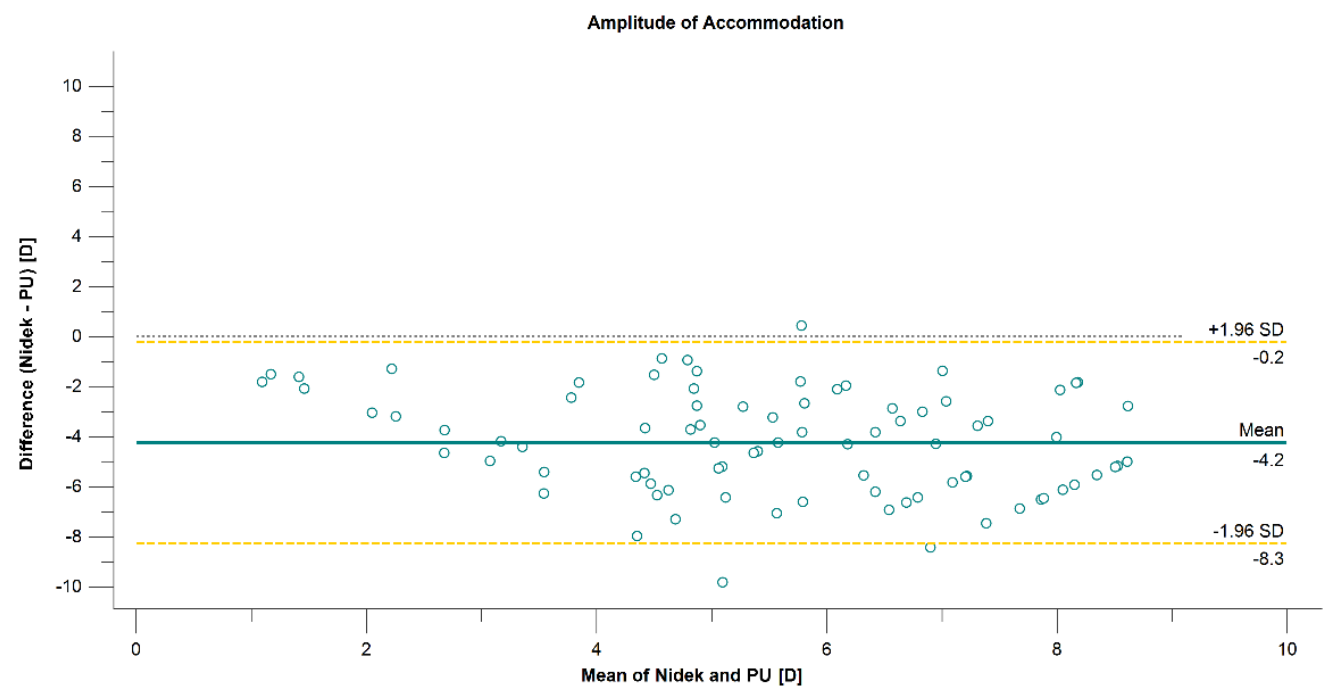

Figure 3. Agreement in amplitude-of-accommodation measurements between the Nidek autorefractor and the push-up (PU) method associated with a 95\% CI for difference.

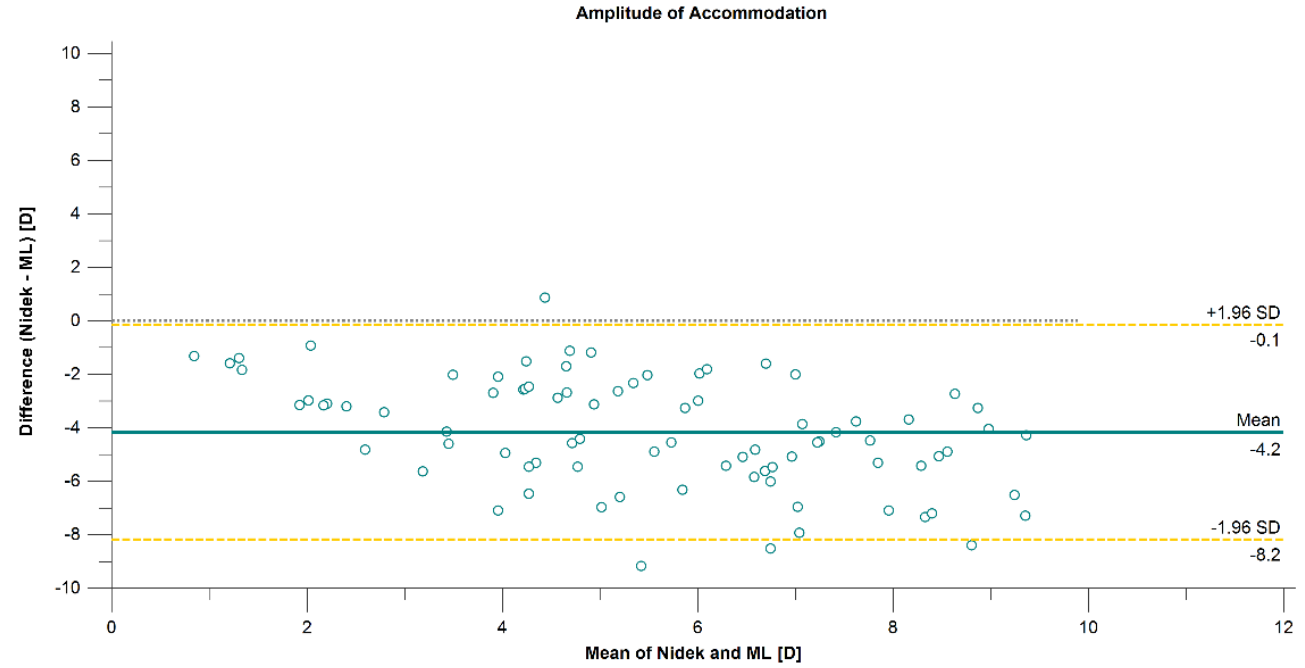

Figure 4. Agreement in amplitude-of-accommodation measurements between the Nidek autorefractor and the minus-lens (ML) method associated with 95\% CI for difference. 


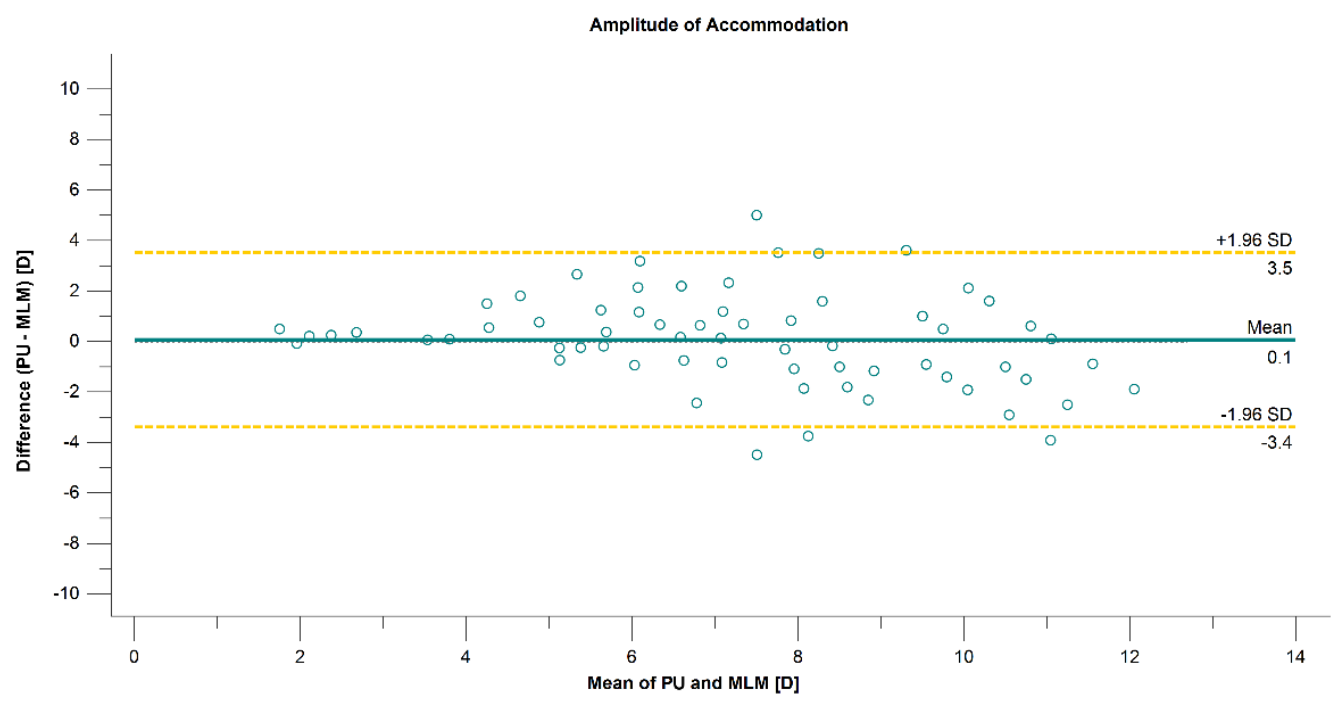

Figure 5. Agreement in amplitude-of-accommodation measurements between the push-up and minus-lens methods associated with $95 \%$ CI for difference.

AA as a function of age is illustrated in Figure 6. AA gradually decreased in all three methods; the slope of the decrease was greater in subjective methods. The decrease in AA was more prominent after 31 years of age using objective AA.

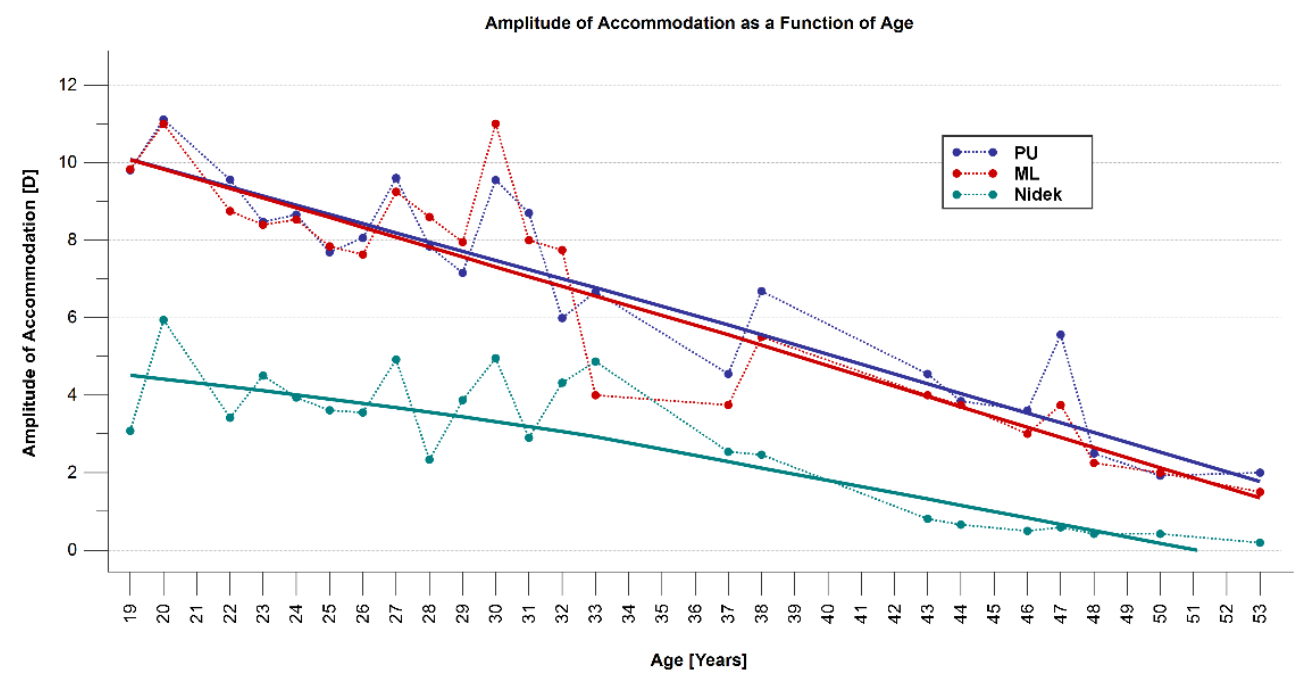

Figure 6. Scatter plot showing the amplitude of accommodation (AA) obtained with all the three methods: subjective push-up (PU), subjective minus-lens (ML), and objective Nidek methods as a function of age.

\section{Discussion}

Subjective measurements overestimate AA compared to objective methods. For example, Ostrin and Glasser reported a difference of up to four diopters in AA measured using subjective techniques compared to objective methods in presbyopic subjects [23]. At approximately 50 years of age, AA evaluated in objective measurements effectively becomes zero [24,25], while the apparent residual $1.00 \mathrm{D}$ accommodation using PU and ML methods really reflects the eye's depth of focus. In optics, the depth of focus is the distance through which the test target can be displaced without initiation of the perception of blur; the smaller the aperture, the wider the depth of field. Thus, greater retinal illumination or pupil constriction without an increase in illumination, e.g., due to an accommodative stimulus, would increase the depth of field. It was hypothesized that subjective AA assessment is an inadequate measure to evaluate true accommodation, because it fails to 
differentiate between passive depth of focus and an active accommodative power change in the eye $[26,27]$. Some other reasons for this overestimation include relative distance magnification or stimulation of proximal accommodation in the PU method, the influence of the depth of focus, differences in retinal illumination and pupillary size during measurement, and inaccuracies in measuring the distance from the near point of accommodation to the spectacle plane (particularly at shorter distances, where small differences in metric units result in large differences in dioptric equivalents) [28]. Objective techniques might quantify the magnitude of refractive change of the eye to more accurately and precisely depict accommodative ability [23,29]. Particularly in younger age groups, the mean objective amplitudes are approximately half of those measured with the subjective PU test in the same subjects [27].

Moreover, objective AA measurements are known to be greater with the proximal stimulated technique than with lens stimulation $[27,30]$. Table 2 summarizes studies comparing objective AA measurements taken with subjective methods. The specific construction of the Nidek device makes it possible to trigger the accommodative response by only lens stimulation. As this is a closed-field autorefractor, the monocular depth cues are absent, the target size and luminance do not change with the stimulus, and there are no familiarly sized objects and no interposition of targets in depth [31,32]. This could explain why the results are even lower than those with lens-stimulated AA in open-field autorefractors.

Table 2. Studies comparing the objective amplitude of accommodation obtained with commercially available autorefractors inducing $5 \mathrm{D}$ accommodative stimulation using lens or proximity stimulus with subjective measurements.

\begin{tabular}{|c|c|c|c|c|c|c|}
\hline Study & $\begin{array}{c}\text { Age } \\
\text { (Years) }\end{array}$ & $\begin{array}{l}\text { Number } \\
\text { of Eyes }\end{array}$ & Device & $\begin{array}{l}\text { Sub. PU } \\
\text { AA (D) }\end{array}$ & $\begin{array}{l}\text { Obj. Proximal- } \\
\text { Stimulated AA } \\
\text { (D) }\end{array}$ & $\begin{array}{l}\text { Obj. Lens- } \\
\text { Stimulated } \\
\text { AA (D) }\end{array}$ \\
\hline $\begin{array}{l}\text { Anderson } \\
\text { and } \\
\text { Stuebing } \\
\text { [27] }\end{array}$ & $26-30$ & 25 & $\begin{array}{l}\text { Grand Seiko } \\
\text { WAM-5500 }\end{array}$ & $8.45 \pm 2.24$ & $6.05 \pm 1.1$ & $5.7 \pm 1.1$ \\
\hline $\begin{array}{l}\text { Win-Hall } \\
\text { et al. 2007 } \\
{[30]}\end{array}$ & $21-30$ & 22 & $\begin{array}{l}\text { Grand Seiko } \\
\text { WR-5100K }\end{array}$ & $7.74 \pm 0.36$ & $4.68 \pm 0.10 *$ & $4.13 \pm 0.09 *$ \\
\hline $\begin{array}{l}\text { Present } \\
\text { study }\end{array}$ & $19-50$ & 84 & Nidek AR-1a & $7.67 \pm 2.38$ & $\mathrm{~N} / \mathrm{A}$ & $3.43 \pm 1.94$ \\
\hline
\end{tabular}

Potential advantages of automatic objective measurement is the ease of performance, as it only requires one to focus the camera on the center of the pupil and press the trigger; the measurement can be conducted by a less skilled examiner as it does not require evaluation of subjective refraction. Moreover, it excellently fits into the work streaming process. The time required to obtain an objective measurement with the Nidek device might be similar to the subjective assessment by an experienced examiner. The duration of Nidek AA measurement for each eye is up to $30 \mathrm{~s}$; however, it is shorter if no response to the accommodative stimulus is obtained for a few seconds. However, to be able to perform a scan, the patient must be able to fixate sufficiently for up to $30 \mathrm{~s}$ during the measuring process; potentially, this could be problematic when evaluating children, elder patients, and patients with nystagmus.

Assessing AA as a function of age shows that it progressively decreases from around 5 years of age to around 50 years. Clinicians are sometimes surprised that accommodation ceases as soon as the early fifties [25]; the data reported in this study support this view. The variation in accommodative amplitude with age showed that objective AA drops rapidly after about the age of 38 years, which is almost coincident with the age of onset 
of presbyopia, while changes in subjective AA techniques are associated with a gradual decrease even up to the age of 50 years. Age-related changes in objective AA in this study were somewhat curvilinear and did not follow the sinusoidal function with a rapid decrease in accommodation in the age range of 20 to 50 years reported by Anderson et al. [33].

Previous studies have also shown that AA measurements show higher values in the PU method than in the ML technique [4,34]. In our study, measurements were taken in a random order and the difference between the AA assessed with PU and ML methods was less than $0.1 \mathrm{D}$. A variety of factors might influence subjective AA assessment, including variations in RAF ruler manufacture, specification of the measurement endpoint, specification of the reference point of measurement, measurement conditions, consideration of refractive error, and psychological factors $[35,36]$. Atchison et al. recommended using letter discrimination rather than blur perception for the PU method, and the latter method, which was used in our study, could lead to underestimation of AA [37]. Moreover, it is known that for young subjects with high amplitudes, it is difficult to get an accurate measurement in the PU method, as small distance changes correspond to large dioptric values [37].

One could consider that it would be more proper to compare objective findings from the new Nidek device to objective amplitudes obtained with the Grand Seiko open-field autorefractor method mentioned in previous publications. Nevertheless, this study aimed to assess the clinical utility of the new autorefractor by comparing it with the currently used methods. These results could be particularly useful when comparing AA values obtained with conventional subjective methods and the results of Nidek devices.

In conclusion, the objective AA measurements obtained with the new Nidek autorefractor were significantly lower than subjective measurements and showed moderate agreement.

Author Contributions: Concept and design, data collection, data analysis and interpretation, drafting the article, P.K.; conception of the work, statistical analysis, K.P.; conception of the work, critical revision of the article, H.M.-M. and R.K. All authors have read and agreed to the published version of the manuscript.

Funding: This research received no external funding.

Institutional Review Board Statement: The study protocol was approval by the local bioethical committee (Komisja Bioetyczna przy Izbie Lekarskiej w Gdańsku) Approval No. KB-21/20.

Informed Consent Statement: Informed consent was obtained from all subjects involved in the study.

Data Availability Statement: Not applicable.

Acknowledgments: The authors would like to thank David H. Burns from the Institute of Optometry, London, United Kingdom, and Giacomo Savini from the G.B. Bietti Foundation, Rome, Italy, for the critical discussion of the manuscript; Jacek Świeczka for obtaining excellent measurements of AA in our cohort; and Poland Optical, Cieszyn, Poland, for providing the device for the study.

Conflicts of Interest: Kanclerz reports grants from Alcon and non-financial support from Visim and Optopol Technologies, outside the submitted work. Pluta has nothing to disclose. MomeniMoghaddam has nothing to disclose. Khoramnia reports grants, personal fees, and non-financial support from Alimera, Alcon, Bayer, Johnson\&Johnson, Hoya, Novartis, Physiol, Rayner, and Roche and personal fees and non-financial support from Allergan, Kowa, Ophtec, Oculentis/Teleon, Santen, and Acufocus, outside the submitted work. The authors report no conflicts of interest and have no proprietary interest in any of the materials mentioned in this article.

\section{Abbreviations}

AA: amplitude of accommodation; AI: accommodative insufficiency; CI: confidence interval; ML: minus lens; PU: push-up; RAF: Royal Air Force; SD: standard deviation. 


\section{References}

1. Singh, P.; Tripathy, K. Presbyopia. In StatPearls; StatPearls Publishing: Treasure Island, FL, USA, 2021.

2. Rosenfield, M.; Gilmartin, B. Effect of Target Proximity on the Open-Loop Accommodative Response. Optom. Vis. Sci. 1990, 67, 74-79. [CrossRef] [PubMed]

3. Hussaindeen, J.R.; Murali, A. Accommodative Insufficiency: Prevalence, Impact and Treatment Options. Clin. Optom. 2020, 12, 135-149. [CrossRef] [PubMed]

4. Antona, B.; Barra, F.; Barrio, A.; Gonzalez, E.; Sanchez, I. Repeatability Intraexaminer and Agreement in Amplitude of Accommodation Measurements. Graefes Arch. Clin. Exp. Ophthalmol. 2009, 247, 121-127. [CrossRef] [PubMed]

5. Rosenfield, M.; Cohen, A.S. Repeatability of Clinical Measurements of the Amplitude of Accommodation. Ophthalmic Physiol. Opt. 1996, 16, 247-249. [CrossRef]

6. Moore, K.E.; Berntsen, D.A. Central and Peripheral Autorefraction Repeatability in Normal Eyes. Optom. Vis. Sci. 2014, 91, 1106-1112. [CrossRef]

7. Davies, L.N.; Mallen, E.A.H.; Wolffsohn, J.S.; Gilmartin, B. Clinical Evaluation of the Shin-Nippon NVision-K 5001/Grand Seiko WR-5100K Autorefractor. Optom. Vis. Sci. 2003, 80, 320-324. [CrossRef]

8. Mallen, E.A.H.; Wolffsohn, J.S.; Gilmartin, B.; Tsujimura, S. Clinical Evaluation of the Shin-Nippon SRW-5000 Autorefractor in Adults. Ophthalmic Physiol. Opt. 2001, 21, 101-107. [CrossRef]

9. Hunt, O.A.; Wolffsohn, J.S.; Gilmartin, B. Evaluation of the Measurement of Refractive Error by the PowerRefractor: A Remote, Continuous and Binocular Measurement System of Oculomotor Function. Br. J. Ophthalmol. 2003, 87, 1504-1508. [CrossRef]

10. Cleary, G.; Spalton, D.J.; Patel, P.M.; Lin, P.-F.; Marshall, J. Diagnostic Accuracy and Variability of Autorefraction by the Tracey Visual Function Analyzer and the Shin-Nippon NVision-K 5001 in Relation to Subjective Refraction. Ophthalmic Physiol. Opt. 2009, 29, 173-181. [CrossRef]

11. Sheppard, A.L.; Davies, L.N. Clinical Evaluation of the Grand Seiko Auto Ref/Keratometer WAM-5500. Ophthalmic Physiol. Opt. 2010, 30, 143-151. [CrossRef]

12. Nagra, M.; Akhtar, A.; Huntjens, B.; Campbell, P. Open versus Closed View Autorefraction in Young Adults. J. Optom. 2021, 14, 86-91. [CrossRef]

13. Davis, B.; Collins, M.; Atchison, D. Calibration of the Canon Autoref R-1 for Continuous Measurement of Accommodation. Ophthalmic Physiol. Opt. 1993, 13, 191-198. [CrossRef]

14. Momeni-Moghaddam, H.; Goss, D.A. Comparison of Four Different Binocular Balancing Techniques. Clin. Exp. Optom. 2014, 97, 422-425. [CrossRef]

15. Flitcroft, D.I.; He, M.; Jonas, J.B.; Jong, M.; Naidoo, K.; Ohno-Matsui, K.; Rahi, J.; Resnikoff, S.; Vitale, S.; Yannuzzi, L. IMIDefining and Classifying Myopia: A Proposed Set of Standards for Clinical and Epidemiologic Studies. Investig. Opthalmology Vis. Sci. 2019, 60, M20. [CrossRef] [PubMed]

16. Weng, C.-C.; Hwang, D.-K.; Liu, C.J.-L. Repeatability of the Amplitude of Accommodation Measured by a New Generation Autorefractor. PLOS ONE 2020, 15, e0224733. [CrossRef]

17. Kubota, M.; Kubota, S.; Kobashi, H.; Ayaki, M.; Negishi, K.; Tsubota, K. Difference in Pupillary Diameter as an Important Factor for Evaluating Amplitude of Accommodation: A Prospective Observational Study. J. Clin. Med. 2020, 9, 2678. [CrossRef] [PubMed]

18. Burns, D.H.; Allen, P.M.; Edgar, D.F.; Evans, B.J.W. A Review of Depth of Focus in Measurement of the Amplitude of Accommodation. Vision 2018, 2, 37. [CrossRef]

19. Adler, P.; Scally, A.J.; Barrett, B.T. Test-Retest Reproducibility of Accommodation Measurements Gathered in an Unselected Sample of UK Primary School Children. Br. J. Ophthalmol. 2013, 97, 592-597. [CrossRef] [PubMed]

20. Zaki, R.; Bulgiba, A.; Ismail, R.; Ismail, N.A. Statistical Methods Used to Test for Agreement of Medical Instruments Measuring Continuous Variables in Method Comparison Studies: A Systematic Review. PLoS ONE 2012, 7, e37908. [CrossRef] [PubMed]

21. Ratner, B. The Correlation Coefficient: Its Values Range between 1/-1, or Do They? J. Target. Meas. Anal. Mark. 2009, 17, 139-142. [CrossRef]

22. Vanderbilt Biostatistics Wiki-PowerSampleSize. Available online: http://biostat.mc.vanderbilt.edu/twiki/bin/view/Main/ PowerSampleSize (accessed on 25 December 2019).

23. Ostrin, L.A.; Glasser, A. Accommodation Measurements in a Prepresbyopic and Presbyopic Population. J. Cataract. Refract. Surg. 2004, 30, 1435-1444. [CrossRef] [PubMed]

24. Ramsdale, C.; Charman, W.N. A Longitudinal Study of the Changes in the Static Accommodation Response. Ophthalmic Physiol. Opt. 1989, 9, 255-263. [CrossRef] [PubMed]

25. Charman, W.N. The Path to Presbyopia: Straight or Crooked? Ophthalmic Physiol. Opt. 1989, 9, 424-430. [CrossRef]

26. Mathebula, S.D.; Ntsoane, M.D.; Makgaba, N.T.; Landela, K.L. Comparison of the Amplitude of Accommodation Determined Subjectively and Objectively in South African University Students. Afr. Vis. Eye Health 2018, 77, 10. [CrossRef]

27. Anderson, H.A.; Stuebing, K.K. Subjective versus Objective Accommodative Amplitude: Preschool to Presbyopia. Optom. Vis. Sci. 2014, 91, 1290-1301. [CrossRef] [PubMed]

28. Lara, F.; Del Águila-Carrasco, A.J.; Marín-Franch, I.; Riquelme-Nicolás, R.; López-Gil, N. The Effect of Retinal Illuminance on the Subjective Amplitude of Accommodation. Optom. Vis. Sci. 2020, 97, 641-647. [CrossRef] [PubMed] 
29. Wold, J.E.; Hu, A.; Chen, S.; Glasser, A. Subjective and Objective Measurement of Human Accommodative Amplitude. J. Cataract. Refract. Surg. 2003, 29, 1878-1888. [CrossRef]

30. Win-Hall, D.M.; Ostrin, L.A.; Kasthurirangan, S.; Glasser, A. Objective Accommodation Measurement with the Grand Seiko and Hartinger Coincidence Refractometer. Optom. Vis. Sci. 2007, 84, 879-887. [CrossRef]

31. Stark, L.R.; Atchison, D.A. Subject Instructions and Methods of Target Presentation in Accommodation Research. Investig. Ophthalmol. Vis. Sci. 1994, 35, 528-537.

32. Atchison, D.A.; Varnas, S.R. Accommodation Stimulus and Response Determinations with Autorefractors. Ophthalmic Physiol. Opt. 2017, 37, 96-104. [CrossRef]

33. Anderson, H.A.; Hentz, G.; Glasser, A.; Stuebing, K.K.; Manny, R.E. Minus-Lens-Stimulated Accommodative Amplitude Decreases Sigmoidally with Age: A Study of Objectively Measured Accommodative Amplitudes from Age 3. Investig. Ophthalmol. Vis. Sci. 2008, 49, 2919-2926. [CrossRef] [PubMed]

34. Momeni-Moghaddam, H.; Kundart, J.; Askarizadeh, F. Comparing Measurement Techniques of Accommodative Amplitudes. Indian J. Ophthalmol. 2014, 62, 683-687. [CrossRef] [PubMed]

35. Burns, D.H.; Allen, P.M.; Edgar, D.F.; Evans, B.J.W. Sources of Error in Clinical Measurement of the Amplitude of Accommodation. J. Optom. 2020, 13, 3-14. [CrossRef] [PubMed]

36. Momeni-Moghaddam, H.; Wolffsohn, J.S.; Azimi, A.; Babaei-Malekkolaei, E. Effect of Target Distance on Accommodative Amplitude Measured Using the Minus Lens Technique. Clin. Exp. Optom. 2014, 97, 62-65. [CrossRef]

37. Atchison, D.A.; Capper, E.J.; McCabe, K.L. Critical Subjective Measurement of Amplitude of Accommodation. Optom. Vis. Sci. 1994, 71, 699-706. [CrossRef] 